\title{
UTILIZAREA ENERGIEI SOLARE IN REALIZAREA CASEI PASIVE INTELIGENTE. STUDII DE CAZ ${ }^{2}$
}

\section{THE EMPLOYMENT OF SOLAR ENERGY IN THE SMART PASSIVE HOUSE. CASE STUDIES ${ }^{3}$}

dr. dipl.-ing./PhD dipl.-eng. Maria Bostenaru-Dan Universitatea de Arhitectură și Urbanism "Ion Mincu"

„Ion Mincu“ University of Architecture and Urban Planning maria.bostenaru@iaim.ro

${ }^{2}$ Studii de caz incluse în COST Action TU1401.

${ }^{3}$ Case studies submitted to the COST Action TU1401. 



\title{
Rezumat
}

În acest articol sunt prezentate studii de caz de utilizare a energiei solare. În timp ce primele studii de caz din România și Italia sunt practici inovative investigate din punctul de vedere al participării publice la implementarea energiei reînnoibile, proiectul din Germania este pentru un centru al mediului unde a fost propusă pentru actori o metodă inovativă de proiectare. Utilizarea energiei solare include elemente fotovoltaice pe acoperiș și energie termală pe acoperiș, dar și principiile casei pasive cu fațade inteligente umbrite și curți interioare închise. În Germania, utilizarea energiei regenerabile este mult mai răspândită decât în celelalte două țări luate în considerație, unde proiectele date ca exemplu sunt proiecte pilot inovative. Ambele au fost gândite ca proiecte de locuire care să fie ulterior convertite în programe de arhitectură universitară. Pentru proiectul demonstrativ ocazia a fost în România un concurs internaţional iar în Italia reconstrucția după cutremurul din 2009 care a afectat L'Aquila. De asemenea, și pentru proiectul propus german a fost un incentiv al propunerii öi anume calitatea de oraș al mediului câștigată de Heidelberg. Studiile de caz au fost cercetate pentru contribuția la grupurile de lucru 2 și 3 ale rețelei COST TU1401 „Energia regenerabilü și calitatea peisajului”, o rețea europeană cuprinzând aproape toate țările Europei, de aici și scara urbană care e mai importantă în aceste proiecte față de clădirea individuală.

Keywords: participare publică, proiectare integrală, energie solară regenerabilă, COST TU1401

\begin{abstract}
In this paper case studies of employment of solar energy are presented. While the first case studies for Romania and Italy are innovative existing practices investigated from the point of view of public awareness of the implementation of renewable energy, the proposal for Germany is one for a dedicated environment centre where also an innovative method of design is considered for the stakeholders. The solar energy methods involved include on-roof photovoltaics and on-roof thermal energy, but also the principles of passive house with intelligent shadowed facades and atria. In Germany renewable energy approaches are much more spread than in the two other countries considered, where the example projects are innovative pilot projects. Both are thought as residential projects to be converted later on to university use. The occasion for this demonstration was given in Romania by a competition and in Italy by the reconstruction following the 2009 L'Aquila earthquake. Also for the German proposed design the quality of environment city of Heidelberg is occasion for the proposed design. The case studies were investigated as contribution to Working Group 2 and Working Group 3 of the COST action TU1401 „Renewable energy and landscape quality”, a European network spanning almost all countries of Europe, hence the urban scale dimension is more important than the individual building.
\end{abstract}

Keywords: public participation, integral design, renewable solar energy, COST TU1401 
Purtătorii de energie fosili sunt epuizabili, lucru care conduce în zilele noastre la orientarea către surse de energie regenerabilă, solară, hidro, eoliană. Utilizarea energiei solare depinde de clima locului unde se află construcția respectivă și nu este un lucru nou. Casa pasivă a existat încă din perioada antichităţii (ex. porticurile din Orientul apropiat pentru umbrirea faţadei) şi este redescoperită în zilele noastre (Goulding et al., 1992, Stahl și Goetzberger, 1990, Gonzalo și Habermann, 2012) inițial în Darmstadt, Germania, în anii 1990.

Din punctul de vedere al conceptului, casa pasivă se clasifică în casa cu pierderi minime (izolată optim) sau casa cu câștiguri solare maxime. În cel de-al doilea caz volumetria și zonificarea clădirii joacă un rol esențial. În cazul câștigurilor solare un rol decisiv îl joacă pe lângă suprafața de absorbție și elementele masive de înmagazinare. Orientarea N-S este cea mai favorabilă. Un concept promovat în Germania care combină cele două este cel al termoizolației transparente. În afară de elementele pasive de utilizare a energiei solare (Schittich, 2003), aceasta poate fi utilizată și activ, prin colectori termici și fotovoltaic.

Acțiunea COST TU1401 "Energie regenerabilă și calitatea peisajului" 1 este o rețea tematică ale cărei activități de colaborare sunt finanțate de Asociația $\operatorname{COST}^{2}$ printr-un contract cu Comisia Europeană. În cadrul rețelei sunt câteva grupuri de lucru incluzând:

- Recenzia sistematică a impactului energiei reînnoibile asupra calităţii peisajului

- Studii de caz strategice ale senzitivităţii/potenţialului în termini de energie reînnoibilă

- Aspecte socio-culturale ale producerii durabile de energie reînnoibilă

- Sinteza rezultatelor și difuzarea acestora.

Studiile de caz propuse spre investigare sunt transcendente grupurilor de lucru 2 şi 3, cu un chestionar comun. Din partea României am inclus în cercetare studii de caz legate de energia solară și de hidroenergie, primele fiind presentate aici.

\section{Studiul de caz 1: Casă pasivă în România3 2014, Cité du Soleil, Versailles, France și București, România, echipa EfdeN, coordonator arhitectură Dorina Tărbujaru}

\subsection{Informația de bază privind proiectul}

Acest proiect se regăsește în formă construită în România după un proiect din anii 2014/15 ((Fig. 1: Casa pasivă EfdeN, 2014, echipa EfdeN, foto M. Bostenaru, 2016). Proiectul a fost realizat ca parte a unei expoziții internaționale de arhitectură, o tradiție în promovarea de construcții inovative în alte țări europene și în lume. Expoziția de arhitectură are loc sub formă de concurs, Solar Decathlon, care din 2010 are loc și în Europa (din 2002 în SUA) și în continuare alte regiuni s-au atașat. Începând cu 2012, la Madrid, România a participat la concurs și a expus în așa numitul temporar Oraș al Soarelui (Mihăescu și Ghilduș, 2012, Onescu-Tărbujaru și Leca, 2014). După expoziție, construcțiile sunt valorificate în țară.

\footnotetext{
${ }^{1}$ http://cost-rely.eu/

${ }^{2} \mathrm{http}: / / \mathrm{www} \cdot \operatorname{cost} . \mathrm{eu} /$

${ }^{3} \mathrm{http}$ ://efden.org/
} 
Fossil energy sources are limited, fact which leads nowadays to the orientation towards renewable energy: solar, hydro and wind. The employment of solar energy depends on the climate of the place where the respective construction is placed and is not something new. The passive house existed from times of Antiquity (ex. the porticos in the Middle East for shadowing the façade) and is rediscovered nowadays (Goulding et al., 1992, Stahl and Goetzberger, 1990, Gonzalo and Habermann, 2012), starting with Darmstadt, Germany, in the 1990s.

From the point of view of the concept, the passive house is classified in the house with minimal loss (optimally thermo-insulated) or the house with maximum solar gain. In the second case the volume and the zoning of the house play an essential role. In case of solar gain a deciding role is played besides of the absorption surface by the massive storage elements. The $\mathrm{N}-\mathrm{S}$ orientation is the most favorable one. A concept promoted in Germany which combines the two is the transparent thermal insulation. Apart of the passive elements to use solar energy (Schittich, 2003), this can be also actively used, through thermal collectors and photovoltaic.

The COST Action TU1401 "Renewable energy and landscape quality"4 is a thematic network the networking activities of which are funded by the COST Association ${ }^{5}$ over a contract of the European Commission. There are several working groups, including:

- Systematic review of RE impacts on landscape quality

- Strategic case studies on landscape sensitivity/potentials in terms of renewable energy

- Socio-cultural aspects of sustainable RE production

- Synthesis of findings and dissemination.

The case studies proposed for investigation are across WG2 and WG3, with a common questionnaire. From the side of Romania we proposed case studies related to solar energy and to hydro energy, the first being presented here.

\section{Case study 1: Passive house in Romania6 2014, Cité du Soleil, Versailles, France and Bucharest, România, team EfdeN, coordinator for architecture Dorina Tărbujaru}

\subsection{Basic information about the project}

This project is now found as a built house in Bucharest, Romania, after a 2014/15 project (Fig. 1: EfdeN passive house, 2014, EfdeN team, Photo M. Bostenaru, 2016). The project was done as part of an international architecture exhibition, a tradition in promoting innovative constructions in other European countries and in the world. The architecture exhibition takes place as a competition, Solar Decathlon, which since 2010 found resonance also in Europe (since 2002 in the US) and after that also other regions joined. Starting with 2012 in Madrid, also Romania participated to the competition and displayed solutions in the so-called temporary City of the Sun (Mihăescu and Ghilduş, 2012, Onescu-Tărbujaru and Leca, 2014). After the exhibition the constructions are used in the own country.

\footnotetext{
${ }^{4}$ http://cost-rely.eu/

${ }^{5} \mathrm{http}: / / \mathrm{www} \cdot \operatorname{cost} . \mathrm{eu} /$

${ }^{6} \mathrm{http}$ ://efden.org/
} 
O echipă interdisciplinară compusă din câteva universități din București a reprezentat România în 2014 la Solar Decathlon la Versailles în Franța ${ }^{7}$ între 24 de participanți, incluzând București (Onescu-Tărbujaru et al, 2015) și Timișoara din România. Perioada de pregătire pentru concursul iniţiat de departamentul de energie din SUA începând cu 2002 este de 2 ani și se desfășoară pe mai multe categorii (Europa, SUA; Orientul apropiat). În 2013 a avut loc o ediție în China. Tema concursului în acel an a fost construirea unei case pentru un cartier dens, respectând principiile casei pasive. Soluția românească a fost EfdeN, care a fost reconstruită în curtea Facultății de Instalații, ca primul Centru de Cercetare pentru condițiile de confort. Universităţile partener au fost:

- Universitatea de Arhitectură şi Urbanism "Ion Mincu"

- Universitatea Tehnică de Construcții București (construcții civile, instalații, inginerie în limbi străine)

- Universitatea Politehnică București

- Universitatea de Științe Agronomice și Medicină Veterinară.

A fost sprijinită și de Ministerul Educației și Cercetării.

Aceasta a fost a doua participare la Solar Decathlon după una anterioară numită Prispa (Schoof, 2012) care se baza pe un tip de locuință rurală inspirată de spațiul intermediar din arhitectura tradiţională. Acea casă a fost vândută privat ulterior. Următoarea provocare este participarea la Solar Decathlon Dubai 2018.

Conform clasificării din rețeaua COST grupului de lucru 1 proiectul include energie solară și anume fotovoltaice solare pe acoperiș și energie termală solară pe acoperiș, precum și energie termală ambientală.

Proiectul a fost finanțat prin sponsorizări. Dimensiunea proiectului de energie reînnoibilă este de $130 \mathrm{~m}^{2}$ suprafață desfășurată netă pentru o locuință. Conform nomenclaturii CORINE de utilizare a terenului este o suprafață artificial (țesut urban). Funcțiunile de peisaj sunt: rezidențial (proiectat pentru Solar Decathlon ca locuință), transport (în oraș) și altele (centru de cercetare universitar).

\subsection{Informație privind participarea publică}

Privind implicarea actorilor (Tabel 1: Angajarea actorilor în implementare) în comparație cu implicarea publicului larg, casa este deschisă publicului și participă la evenimente. Participarea publică în România în general este limitată, dar abordarea participativă a permis luarea în considerare a acesteia în cazul EfdeN. Privind scopul de participare, casa a fost prezentată în faza de proiect la numeroase evenimente acest lucru fiind parte integrantă a concursului.

Experiența locală în luarea deciziilor privind problemele de energie este limitată iar acesta a fost un obiect de expoziție.

Privind scopurile actorilor (Tabel 2: Activitățile actorilor), calitatea vizuală privind arhitectura a fost unul din aspectele evaluate în cadrul concursului Solar Decathlon.

\footnotetext{
${ }^{7}$ http://www.solardecathlon2014.fr/en/
} 
An interdisciplinary team from several universities in Bucharest represented Romania in 2014 at Solar Decathlon in Versailles, France ${ }^{8}$ among 24 participants, including also Bucharest (Onescu-Tărbujaru et al, 2015) and Timișoara in Romania. The preparation period for the competition started bz the Energy Department in the USA in 2002 is 2 years and the competition includes more categories (Europe, US, Middle East, China). The topic of the year was to build a house for a dense Siedlung, respecting the principles of the passive house. The Romanian solution was EfdeN, which was rebuilt in the courtyard of the Faculty of installations as First Center of Research for Comfort Conditions. Partner universities were:

- "Ion Mincu” University of Architecture and Urbanism

- Technical University of Constructions Bucharest (civil constructions, installations, engineering in foreign languages)

- Bucharest Polytechnical University

- University of Agronomy Sciences and Veterinary Medicine.

It was supported also by the Ministry of Education and Research.

It was the second participation to Solar Decathlon after a previous one with the project called Prispa (Schoof, 2012) which built on a rural housing type inspired from the intermediary space in peasant architecture. That house was afterwards sold privately. The next challenge will be to participate to Solar Decathlon Dubai.

According to the COST action WG1 classification the project includes solar energy, namely solar PV on-roof power and solar thermal on-roof power, as well as environmental thermal energy.

The project was financed through sponsorship. The size of the RE project is Net Floor Area : $130 \mathrm{~m}^{2}$ for one dwelling. According to CORINE land cover nomenclature it is an artificial surface (urban fabric). Landscape functions are: residential (Designed for Solar Decathlon as residence), transportation (in the city) and other (University research centre).

\subsection{Information about public participation}

Regarding involvement of stakeholders (Tabel 1: Engaging stakeholders in implementation) against involvement of general public, the house is open to the public and participates to events. Public participation in Romania is limited, but the interdisciplinary approach permitted considering it. Regarding the participation goal, the house was presented during the design phase to the public at a number of events as this was part of the competition.

Local experience in decision-making process regarding energy issues is limited, this is an exhibition item.

Regarding concerns of the stakeholders (Tabel 2: Activities of stakeholders), visual quality regarding architecture was one of the items judged in frame of the Solar Decathlon competition.

\footnotetext{
${ }^{8}$ http://www.solardecathlon2014.fr/en/
} 
Tabel 1: Angajarea actorilor în implementare

\begin{tabular}{|l|l|l|}
\hline \multicolumn{1}{|c|}{ actor } & \multicolumn{1}{|c|}{ rol } & \multicolumn{1}{c|}{$\begin{array}{c}\text { Nivelul de influență asupra } \\
\text { implementării }(1 / 2 / 3)^{9}\end{array}$} \\
\hline $\begin{array}{l}\text { 6 investitori au fost implicați } \\
\text { cum scrie pe sit prin parteneriat } \\
\text { între mediul public și mediul } \\
\text { privat }\end{array}$ & $\begin{array}{l}\text { Finanțarea proiectului inclusiv } \\
\text { de ex. donarea de materiale }\end{array}$ & 3 \\
\hline Universitățile & $\begin{array}{l}\text { Studenții au aparținut } \\
\text { universităților și au desfășurat } \\
\text { lucrările ca activitate } \\
\text { extracuriculară }\end{array}$ & 3 \\
\hline Solar Decathlon ${ }^{10}$ & $\begin{array}{l}\text { Concursul a constituit cadrul } \\
\text { și vizibilitatea proiectului }\end{array}$ & 3 \\
\hline
\end{tabular}

Tabel 2: Activitățile actorilor

\begin{tabular}{|l|l|l|}
\hline \multicolumn{1}{|c|}{ faza } & \multicolumn{1}{|c|}{ Tipul de participare } & \multicolumn{1}{c|}{ intensitatea $^{11}$} \\
\hline $\begin{array}{l}\text { Înainte de începerea proiectului } \\
\text { (e.g. contribuția la dezvoltarea } \\
\text { procesului, cercetare, analiză } \\
\text { etc.) }\end{array}$ & $\begin{array}{l}\text { Informație (Tabel 3: Tehnici } \\
\text { de împărțire a informației) }\end{array}$ & 3 \\
\hline Determinarea nevoilor & & 1 \\
\hline Pregătirea proiectului & $\begin{array}{l}\text { Informație (Tabel 4: Tehnici } \\
\text { de schimb de puncte de vedere } \\
\text { intre actori) }\end{array}$ & 2 \\
\hline Proiectarea spațială & Informație & 1 \\
\hline Autorizațiile & Informație & 1 \\
\hline Construcția & Informație & 3 \\
\hline Operarea & Informație & 1 \\
\hline Închiderea & & 3 \\
\hline $\begin{array}{l}\text { După proiect (e.g. contribuție } \\
\text { ulterioară la îmbunătățirea } \\
\text { procesului, dezvoltare de model } \\
\text { etc.) }\end{array}$ & & 2 \\
\hline
\end{tabular}

\footnotetext{
${ }^{9} 1$ scăzută, 2 medie, 3 ridicată

${ }^{10} \mathrm{https}$ ://www.solardecathlon.gov/

11 scăzută, 2 medie, 3 ridicată
} 
Tabel 1: Engaging stakeholders in implementation

\begin{tabular}{|l|l|l|}
\hline \multicolumn{1}{|c|}{ actor } & \multicolumn{1}{|c|}{ role } & \multicolumn{1}{|c|}{$\begin{array}{l}\text { level of influence on the } \\
\text { implementation }(1 / 2 / 3)^{12}\end{array}$} \\
\hline $\begin{array}{l}6 \text { investors were involved as said } \\
\text { on the website through public } \\
\text { private partnership }\end{array}$ & $\begin{array}{l}\text { Financing the project } \\
\text { including for example } \\
\text { donation of materials }\end{array}$ & 3 \\
\hline universities & $\begin{array}{l}\text { The students belonged to the } \\
\text { universities, and they did the } \\
\text { work as extracurricular } \\
\text { activity }\end{array}$ & 3 \\
\hline Solar Decathlon ${ }^{13}$ & $\begin{array}{l}\text { The competition provided the } \\
\text { framework and the visibility }\end{array}$ & 3 \\
\hline
\end{tabular}

Tabel 2: Activities of stakeholders

\begin{tabular}{|c|c|c|}
\hline phase & type of participation & intensity $^{1}$ \\
\hline $\begin{array}{l}\text { Before the project started (e.g. } \\
\text { contribution to the process } \\
\text { development, research, analysis } \\
\text { etc.) }\end{array}$ & $\begin{array}{l}\text { Information (Tabel 3: } \\
\text { Techniques to share } \\
\text { information) }\end{array}$ & 3 \\
\hline Determination of need & & 1 \\
\hline Project preparation & & 1 \\
\hline Spatial planning & $\begin{array}{l}\text { Information (Tabel 4: } \\
\text { Techniques to exchange } \\
\text { viewpoints among } \\
\text { stakeholders) }\end{array}$ & 2 \\
\hline Permitting & & 1 \\
\hline Construction & Information & 1 \\
\hline Operation & Information & 3 \\
\hline Closing & information & 1 \\
\hline $\begin{array}{l}\text { After the course of the project } \\
\text { (e.g. subsequently contribution } \\
\text { to the process improvement, } \\
\text { model development etc.) }\end{array}$ & information & 3 \\
\hline
\end{tabular}

\footnotetext{
121 low, 2 medium, 3 high

${ }^{13} \mathrm{https}$ //www.solardecathlon.gov/

141 low, 2 medium, 3 high
} 
Cel mai bun punctaj la concursul Solar Decathlon a fost obținut pentru arhitectură (120 din 120). Soluția depășește uniformitatea pe care ar putea-o avea cartierele solare datorită orientării lor spre punctele cardinale. Tot 120 de puncte au fost obținute în concurs în bilanțul de energie electrică, confort și funcțiune, prin monitorizare. Problemele de mediu au fost parte a judecăţii (emisii, încălzire, apă, confort). De fapt confortul este subiectul centrului de cercetare din casă. Deșeurile au fost parte a conceptului de energie, recuperându-se energie din acestea. Costurile sunt moderate pentru o clădire atât de inovativă. (Cost $/ \mathrm{m}^{2}: 1342 € / \mathrm{m}^{2}$, Cost/locuință: $174483 € /$ locuință).

\section{Tabel 3: Tehnici de împărțire a informației}

\begin{tabular}{|l|c|c|}
\hline \multicolumn{1}{|c|}{ ÎMPĂRȚIREA INFORMAȚIEI } & TEHNICA & COMENTARIU \\
\hline $\begin{array}{l}\text { Campanii de mediatizare } \\
\text { Linii telefonice, chioșcuri de } \\
\text { informare, târguri și evenimente }\end{array}$ & $\mathbf{x}$ & $\begin{array}{c}\text { Conceptul a fost prezentat la } \\
\text { numeroase târguri și evenimente, } \\
\text { inclusiv publicații }\end{array}$ \\
\hline $\begin{array}{l}\text { Informație/Programe educaționale } \\
\text { Birouri pe teren, depozite de } \\
\text { informații, situri Web, contacte de } \\
\text { informație centrală, sumar }\end{array}$ & $\mathbf{x}$ & $\frac{\text { http://www.construction21.org/case- }}{\text { studies/h/efden-4c.html }}$ \\
\hline
\end{tabular}

Tabel 4: Tehnici de schimb de puncte de vedere între actori

\begin{tabular}{|l|c|c|}
\hline \multicolumn{1}{|c|}{$\begin{array}{c}\text { ADUCEREA OAMENILOR ÎN } \\
\text { COMUNITATE }\end{array}$} & TEHNICA & COMENTARIU \\
\hline $\begin{array}{l}\text { Forumuri publice deschise } \\
\text { Întâlniri publice, casa deschisă, cercuri } \\
\text { samoane/conversații recurente, } \\
\begin{array}{l}\text { Workshopuri, procese acvariu, întâniri } \\
\text { asistate de calculator, simpozioane, tururi și } \\
\text { deplasari pe teren }\end{array}\end{array}$ & $\mathbf{x}$ & $\begin{array}{c}\text { Casa deschisă e un program la } \\
\text { care participă }\end{array}$ \\
\hline
\end{tabular}

Ca rezultat al participării, proiectul este cunoscut publicului larg. Privind circulaţia informației, pentru o casă nouă abordarea este inovativă în România, pentru că în mod curent clădirile noi de locuit din România sunt clădiri private și nu sunt gândite pentru participarea unor locatari diferiți de investitor cum este cazul în Europa de Vest. Proiectul a obținut la concursul Solar Decathlon 80 de puncte din 120 în conștiința socială și comunicare. Transportul urban și accesibilitatea au fost de asemenea 80 de puncte împreună cu inovarea în construcții și eficiență energetică. Durabilitatea a avut 100 de puncte.

Ca lecții învățate, casa ar putea deveni un exemplu de cea mai bună practică pentru arhitectura efemeră care devine permanentă în România, întrucât este un prototip. În țările din vest este un program de arhitectură pentru case passive care include și obiecte de comparație (ex. DIAS), este încă nevoie de o bază de date în România. Totuși, Construction21 promovează astfel de case. Cunoaștem case passive proiectate de arh. Sergiu Petrea cum ar fi 
The best points in the contest Solar Decathlon were obtained for architecture (120 from 120). The solution overcomes the uniformity which solar Siedlungen might have with their cardinal points orientation. 120 points were also in electrical energy balance, comfort and function, through monitoring. Environmental issues are also part of the judgment (emissions, heat, water, comfort). Actually the comfort is what the research centre in this house is dealing with. Waste was part of the energy concept, used for energy recovery. Costs are moderate for such an innovative building (Cost $/ \mathrm{m}^{2}: 1342 € / \mathrm{m}^{2}$, Cost/Dwelling: $174483 € /$ Dwelling).

Tabel 3: Techniques to share information

\begin{tabular}{|l|c|c|}
\hline \multicolumn{1}{|c|}{ SHARE INFORMATION } & TECHNIQUE & COMMENT \\
\hline $\begin{array}{l}\text { Awareness Campaigns } \\
\text { Telephone Hotlines, Information Kiosks, } \\
\text { Fairs and Events }\end{array}$ & $\mathbf{x}$ & $\begin{array}{c}\text { The concept was presented at } \\
\text { numerous fairs and events, } \\
\text { including publications }\end{array}$ \\
\hline $\begin{array}{l}\text { Information/Education Programs } \\
\text { Field Offices, Information Repositories, } \\
\text { World Wide Web sites, Central } \\
\text { Information Contacts, Briefings }\end{array}$ & $\mathbf{x}$ & $\frac{\text { http://www.construction21.org/case- }}{\frac{\text { studies/h/efden-4c.html }}{\text { http://efden.org/ }}}$ \\
\hline
\end{tabular}

Tabel 4: Techniques to exchange viewpoints among stakeholders

\begin{tabular}{|l|c|c|}
\hline \multicolumn{1}{|c|}{ BRINGING PEOPLE TOGETHER } & TECHNIQUE & COMMENT \\
\hline Open Public Forums & $\mathbf{x}$ & $\begin{array}{c}\text { Open house is a programme it } \\
\text { participates to }\end{array}$ \\
$\begin{array}{l}\text { Public Meetings, Open Houses, Samoan } \\
\text { Circles/Revolving Conversations, } \\
\begin{array}{l}\text { Workshops, Fishbowl Processes, Computer- } \\
\text { assisted meetings, Symposia, Tours and } \\
\text { Field Trips }\end{array}\end{array}$ & & \\
\hline
\end{tabular}

As a participation outcome the project is well known. Regarding innovation, for a new house it is innovation in Romania, as usually new individual houses in Romania are private buildings and not thought for participation of inhabitants different of the investor as in Western Europe. The project obtained at the Solar Decathlon competition 80 points out of 120 in social conscience and communication. Urban transport and accessibility were also 80 points along with innovation and civil engineering and energy efficiency. Sustainability had 100 points.

As lessons learned, it could become a best practice example for ephemeral architecture becoming permanent in Romania, as it is a prototype. In Western countries there is software providing examples of passive houses together with computations (ex. DIAS), for a database for Romania there is still some need. However, Construction21 promotes such houses, (references below). I have knowledge also of passive houses designed by architect Sergiu 
CHE: casă în standard pasiv construită la Izvoarele Cetății ${ }^{1516}$, județul Suceava, România (care a obținut premiul Saint Gobain la Anuala de arhitectură din $2015^{17}$ ) precum și CASA E4 Nearly Zero Energy Building în satul Ostratu lângă București ${ }^{18}$. Totuși, acestea sunt case individuale nu prevăzute pentru un cartier precum EfdeN.

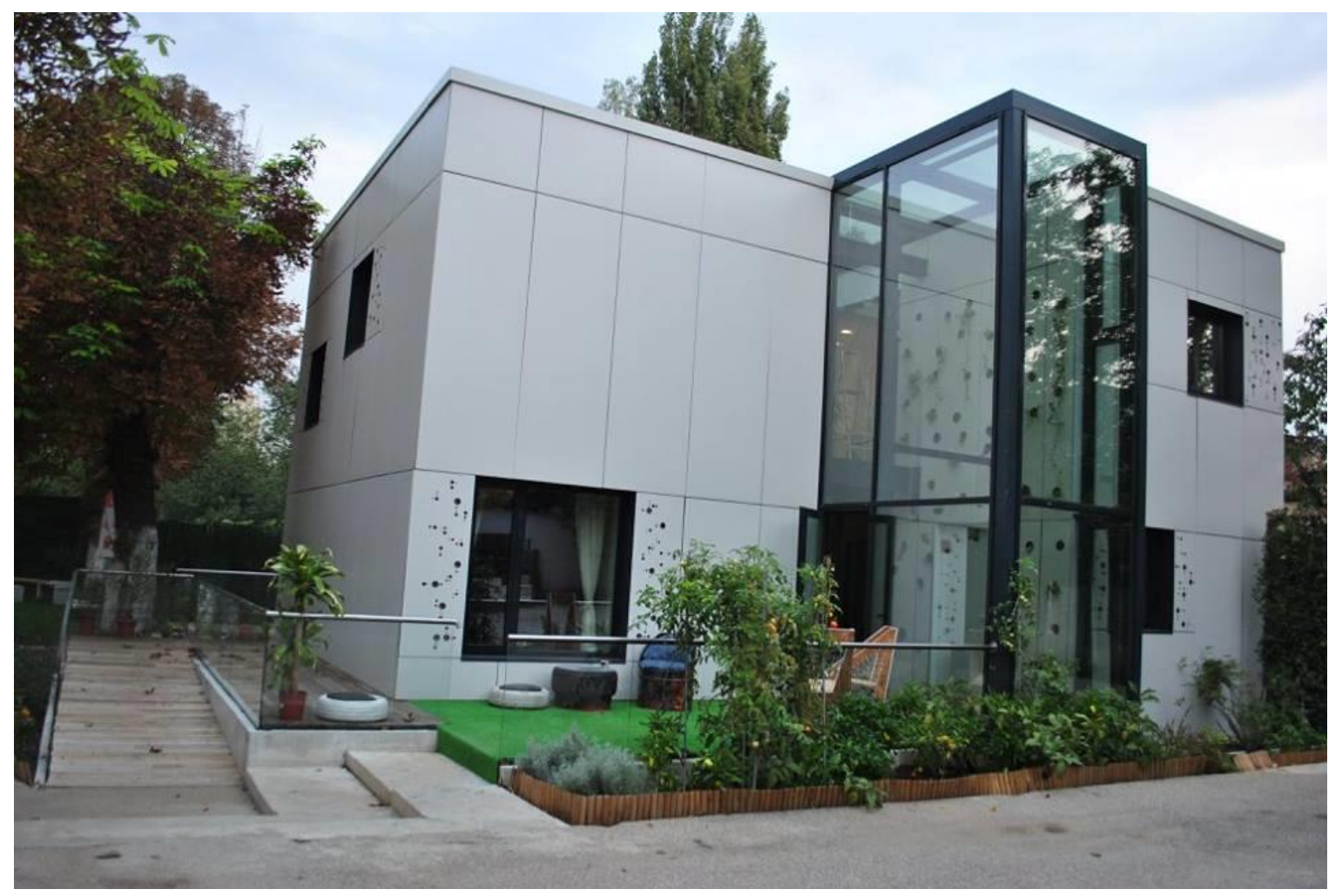

Fig. 1: Casa pasivă EfdeN, 2014, echipa EfdeN, foto M. Bostenaru, 2016

EfdeN passive house, 2014, EfdeN team, photo M. Bostenaru, 2016

2. Studiul de caz 2: C.A.S.E. L'Aquilla, Italia, 2009-2010, proiecte de Wood Beton, Consorzio Stabile Consta, Consorzio Etruria, Costruzioni G. Maltauro, Coge Costruzioni Generali, Ing. Armido Frezza, Meraviglia, Eschilo, Iter Gestione e Appalti, Donati, Consorzio Stabile Arcale, D'Agostino Costruzioni Generali, Orceana Costruzioni, Imprese Costruzioni Pellegrini, Cosbau, Ille Prefabricati

\subsection{Informație de bază despre proiect}

L'Aquila Progetto C.A.S.E. a fost dezvoltat între Aprilie 2009- Aprilie 2010 în L'Aquila, Abruzzo, Italia (Fig. 2: Energie solară fotovoltaică la L'Aquila, Italia, Progetto C.A.S.E. 20092010. Foto: M. Bostenaru, 2010.)

\footnotetext{
${ }^{15} \mathrm{http}: / /$ www.buildup.eu/sites/default/files/content/PASSIVEHOUSECHE.pdf

${ }^{16} \mathrm{https}: / /$ www.construction21.org/case-studies/h/passive-house-che.html

${ }^{17} \mathrm{https}: / /$ www.anuala.ro/proiecte/2015/015/

$18 \mathrm{https} / / /$ www.anuala.ro/proiecte/2016/111/
} 
Petrea as passive house CHE built at Izvoarele Cetății ${ }^{1920}$, Suceava county, Romania (which obtained the Saint Gobain prize at the Architecture Annual in $2015^{21}$ ) as well as CASA E4 Nearly Zero Energy Building in the village Ostratu near Bucharest ${ }^{22}$. However, these are individual houses and not foreseen for a Siedlung as in case of EfdeN.

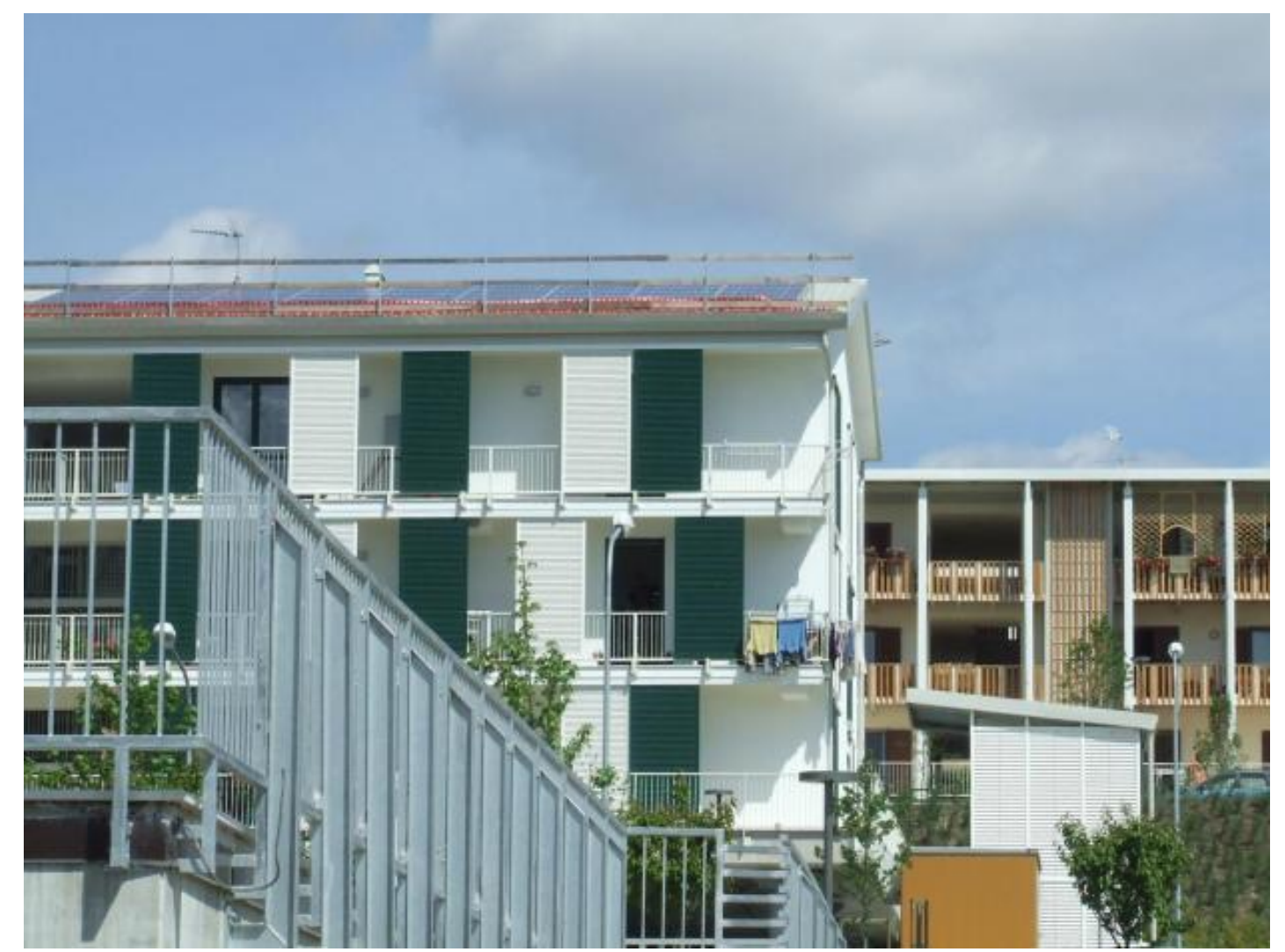

Fig. 2: Energie solară fotovoltaică la L'Aquila, Italia, Progetto C.A.S.E. 2009-10. Foto: M. Bostenaru, 2010. Solar PV on-roof energy at L'Aquila Progetto C.A.S.E. Photo: M. Bostenaru, 2010.

2. Case study 2: C.A.S.E. L'Aquila, Italy, 2009-2010, projects by Wood Beton, Consorzio Stabile Consta, Consorzio Etruria, Costruzioni G. Maltauro, Coge Costruzioni Generali, Ing. Armido Frezza, Meraviglia, Eschilo, Iter Gestione e Appalti, Donati, Consorzio Stabile Arcale, D'Agostino Costruzioni Generali, Orceana Costruzioni, Imprese Costruzioni Pellegrini, Cosbau, Ille Prefabricati

\subsection{Basic information about the project}

L'Aquila Progetto C.A.S.E. was developped April 2009- April 2010 in L'Aquila, Abruzzo, Italy (Fig. 2: Solar PV on-roof energy at L'Aquila Progetto C.A.S.E. Photo: M. Bostenaru, 2010.).

\footnotetext{
${ }^{19} \mathrm{http}: / /$ www.buildup.eu/sites/default/files/content/PASSIVEHOUSECHE.pdf

${ }^{20} \mathrm{https}: / /$ www.construction21.org/case-studies/h/passive-house-che.html

${ }^{21} \mathrm{https}: / /$ www.anuala.ro/proiecte/2015/015/

22 https://www.anuala.ro/proiecte/2016/111/
} 
În 2009 un cutremur puternic a lovit centrul istoric al L'Aquila. Construcțiile din centrul istoric au fost sprijinite, dar nu restaurate, din lipsă de fonduri, așa că pentru relocarea locuitorilor au fost construite cartiere în jurul orașului L'Aquila. Aceste cartiere noi includ energie regenerabilă cum ar fi cea solară. Într-un timp record, câteva noi cartiere au fost construite la periferia orașului, în mediul rural. Ele au folosit moduri moderniste de proiectare din perioada interbelică. Inovativă a fost protecția la seisme, cu izolare la bază, dar și proiectarea eficientă energetic. Astfel, ele sunt un exemplu de cartiere eficiente energetic, și răspund la întrebări privind aspectele în care un cartier poate răspunde la provocările de azi în locul celor din perioada interbelică. Utilizarea energiei regenerabile include panouri solare, integrate în clădiri. C.A.S.E. înseamnă "case" în italiana, dar este și acronimul pentru Complessi Antisismici Sostenibili ed Ecocompatibili (Calvi și Spazianti, 2009, Turini, 2010).

$7000 \mathrm{~m}^{2}$ de panouri solare au fost instalate pe acoperișul fiecărei clădiri pentru producerea apei calde. Puterea medie instalată pentru o clădire: $115 \mathrm{KWt}(4 \mathrm{KWt}$ mean value for a dwelling); 35 mii de mp de panouri fotovoltaice pe acoperiș instalate pe acoperișurile clădirilor și parcări. Puterea medie instalată pe clădire: $25,12 \mathrm{KWp}$ (mai mult de $1 \mathrm{KWp}$ valoare medie pe locuință) (Tabel 5: Clasificarea grupului de lucru 1 al rețelei COST a tipului de proiect de energie regenerabilă.)

Tabel 5: Clasificarea grupului de lucru 1 al rețelei COST a tipului de proiect de energie regenerabilă.

\begin{tabular}{|l|l|l|c|}
\hline Sursa & & & Mărimea în MW \\
\hline \multirow{3}{*}{ Energie solară } & Fotovoltaice solare la nivelul solului & $\square$ & \\
\cline { 2 - 5 } & Fotovoltaice solare pe acoperiș & $\square$ & 115 \\
\hline & Energie termală solară la nivelul solului & $\square$ & \\
\cline { 2 - 5 } & Energie termală solară pe acoperiș & $\bigotimes$ & 25,12 \\
\hline
\end{tabular}

Finanțarea proiectului a fost din fonduri publice naţionale.

Suprafața proiectului a fost $1.600 .000 \mathrm{~m}^{2}$. Conform nomenclaturii CORINE de utilizare a terenului, proiectul este o zonă agricolă eterogenă (zonă rurală în regiune montană). Funcțiunile de peisaj sunt rezidențiale (cartiere nou construite) și producție agricolă (zonă rurală).

\subsection{Informație privind participarea publică}

Publicul larg nu a fost implicat (Fig. 3: Protestul locatarilor la L'Aquila. Foto: M. Bostenaru, 2010.) (Bostenaru, 2014, Cerqua și Rapicetta, 2014). C.A.S.E. a fost un proiect condus de Protecția Civilă Italiană. Construcția a fost implementată de un consorțiu condus de Gian Michele Calvi din Pavia. Scopul de partecipare a fost confuz (Tabel 6: Implicarea actorilor în implementare).

Experiența anterioară locală în participare nu este cunoscută (Tabelle 7: Activităţile actorilor.). Populația locală și-a exprimat îngrijorarea privind costurile (de ca. 4 ori mai ridicate decât în alte reconstrucții după cutremur) așa cum se vede în fotografie. Mai târziu proiectanții au fost dați în judecată pentru calitatea scăzută a construcțiilor. Deși participarea 
In 2009 a strong earthquake struck the historical city of L'Aquila. The constructions in the historical centre were propped but not restored as they run out of money, so for the displaced inhabitants new neighbourhoods around L'Aquila were built. These new neighbourhoods incorporate RE such as solar power. In a record time span, several new neighbourhoods were built in the outskirts of the city, in rural setting. They followed the modernist ways of planning from the interwar time. Innovative should be the seismic protection, with base isolation, but also energy efficient planning. As such, they build an example of energy efficient Siedlungen, and answer questions regarding on how such a neighbourhood can respond to challenges of today, instead of those of the interwar time. The use of renewable energies included solar panels as well, integrated in the buildings. C.A.S.E. means "houses" in Italian, but also stays for Complessi Antisismici Sostenibili ed Ecocompatibili (Calvi and Spazianti, 2009, Turini, 2010).

7000 sqm of solar panels were installed on the roof of each building for the production of warm water. The medium installed power is for a building: $115 \mathrm{KWt}$ (4 KWt mean value for a dwelling); 35 thousand sqm of PV on-roof panels installed on the roofs of buildings and parkings. Medium installed power for a building: $25,12 \mathrm{KWp}$ (more than $1 \mathrm{KWp}$ mean value for a dwelling) (Tabel 5: COST WG1 classification of the type of RE project.).

Tabel 5: COST WG1 classification of the type of RE project.

\begin{tabular}{|l|l|l|c|}
\hline Source & & & Size in MW \\
\hline \multirow{4}{*}{ Solar energy } & Solar PV ground-mounted power (S) & $\square$ & \\
\cline { 2 - 4 } & Solar PV on-roof power & $\square$ & 115 \\
\cline { 2 - 5 } & Solar thermal ground-mounted power & $\square$ & \\
\cline { 2 - 5 } & Solar thermal on-roof power & $\searrow$ & 25,12 \\
\hline
\end{tabular}

The financing of the project was assured through public national funding.

The site area was $1.600 .000 \mathrm{sqm}$. According to the CORINE land cover nomenclature, the project is a heterogeneous agricultural area (Rural area in a mountainous region). Landscape functions are residential (newly constructed neighbourhoods) and agricultural production (rural area).

\subsection{Information about public participation}

The general public was not involved (Fig. 3: Protest of the inhabitants in L'Aquila. Photo: M. Bostenaru, 2010.) (Bostenaru, 2014, Cerqua and Rapicetta, 2014). It was a project governed by the Italian Civil Protection. It was carried out by a consortium led by Gian Michele Calvi from Pavia. The participation goal was blurred (Tabel 6: Engagement of stakeholders in implementation).

Previous local experience on participation is not known (Tabel 7: Stakeholders activities.). The local population expressed concerns regarding costs (about 4 times higher than in a previous earthquake reconstruction) as you see in the photo. Later on a process was made for low quality. Although the public participation was not innovative, the seismic and energy 
publică nu a fost inovativă, conceptele seismice şi de energie au fost inovative și proiectul a câștigat un premiu la Milano, chiar pentru eficiența costurilor care a fost criticată în procesul de partipare. Se poate învăța din proiect cum să nu reacționăm la provocările secolului al XXIlea privind energia și schimbarea climei cu modul de proiectare interbelic care răspunde cererilor locuinței industrializate.

Tabel 6: Implicarea actorilor în implementare

\begin{tabular}{|l|l|l|}
\hline \multicolumn{1}{|c|}{ actor } & \multicolumn{1}{|c|}{ rol } & \multicolumn{1}{c|}{$\begin{array}{c}\text { Nivel de influență în } \\
\text { implementare }(1 / 2 / 3)^{23}\end{array}$} \\
\hline Guvernul național italian & $\begin{array}{l}\text { Coordonator de proiect, suport } \\
\text { tehnic, relații publice, } \\
\text { susținere financiară }\end{array}$ & 3 \\
\hline Firmele de construcții & Susținere științifică, expert & 3 \\
\hline Sindicatul L'Aquila & proteste & \\
\hline Populația locală & $\begin{array}{l}\text { Reconstrucție alternativă pe } \\
\text { Google Earth }\end{array}$ & \\
\hline
\end{tabular}

Tabel 7: Activităţile actorilor.

\begin{tabular}{|c|c|c|}
\hline faza & Tipul de participare & intensitatea $^{24}$ \\
\hline \multicolumn{3}{|l|}{$\begin{array}{l}\text { Înainte de începerea proiectului } \\
\text { (e.g. contribuția la dezvoltarea } \\
\text { procesului, cercetare, analiză } \\
\text { etc.) }\end{array}$} \\
\hline Determinarea nevoilor & Informație & 1 \\
\hline Pregătirea proiectului & Informație & 1 \\
\hline \multicolumn{3}{|l|}{ Proiectarea spațială } \\
\hline \multicolumn{3}{|l|}{ Autorizațiile } \\
\hline Construcția & Informație & 1 \\
\hline \multicolumn{3}{|l|}{ Folosirea } \\
\hline Dezafectarea & Informație & 1 \\
\hline $\begin{array}{l}\text { După proiect (e.g. contribuție } \\
\text { ulterioară la îmbunătățirea } \\
\text { procesului, dezvoltare de model } \\
\text { etc.) }\end{array}$ & Informație & 1 \\
\hline
\end{tabular}

231 scăzută, 2 medie, 3 ridicată

${ }^{24} 1$ scăzută, 2 medie, 3 ridicată 
concepts were innovative and the project won a prize in Milan, even for the cost efficiency which was criticized in the participation process. One could learn from the project how not to react at the challenges of the $21^{\text {st }}$ century regarding energy and climate change with the interwar planning methods which respond to the issues of industrialization of housing.

Tabel 6: Engagement of stakeholders in implementation

\begin{tabular}{|l|l|l|}
\hline \multicolumn{1}{|c|}{ actor } & \multicolumn{1}{|c|}{ role } & \multicolumn{1}{c|}{$\begin{array}{c}\text { level of influence on the } \\
\text { implementation }(1 / 2 / 3)^{25}\end{array}$} \\
\hline National government & $\begin{array}{l}\text { Project coordinator, technical } \\
\text { support, PR, financial support }\end{array}$ & 3 \\
\hline Construction companies & Scientific support, expert & 3 \\
\hline L'Aquila sindicate & protests & $\begin{array}{l}\text { Alternative rebuild on Google } \\
\text { Earth }\end{array}$ \\
\hline Local population & & \\
\hline
\end{tabular}

Tabel 7: Stakeholders activities.

\begin{tabular}{|c|c|c|}
\hline phase & type of participation & intensity $^{26}$ \\
\hline \multicolumn{3}{|l|}{$\begin{array}{l}\text { Before the project started (e.g. } \\
\text { contribution to the process } \\
\text { development, research, analysis } \\
\text { etc.) }\end{array}$} \\
\hline Determination of need & information & 1 \\
\hline Project preparation & information & 1 \\
\hline \multicolumn{3}{|l|}{ Spatial planning } \\
\hline \multicolumn{3}{|l|}{ Permitting } \\
\hline Construction & information & 1 \\
\hline \multicolumn{3}{|l|}{ Operation } \\
\hline Closing & information & 1 \\
\hline $\begin{array}{l}\text { After the course of the project } \\
\text { (e.g. subsequently contribution } \\
\text { to the process improvement, } \\
\text { model development etc.) }\end{array}$ & information & 1 \\
\hline
\end{tabular}

\footnotetext{
251 low, 2 medium, 3 high

${ }^{26} 1$ low, 2 medium, 3 high
} 


\section{Proiectul integral „Centru al mediului în Heidelberg“, Germania, 1997, Maria Bostenaru Dan, îndrumare Rüdiger Kramm}

Pentru „Orașul german al mediului“ ${ }^{27}$ Heidelberg am avut sarcina să proiectez ca student la arhitectură la Universitatea din Karlsruhe, în discuție pe sit real cu primarul mediului din Heidelberg, Germania, sub îndrumarea profesorului Rüdiger Kramm pe un sit expus la Römerkreis un centru de mediu: o casă deschisă cu funcțiune mixtă, de la sediul pentru autoritatea mediului, instituții, birouri ale unor firme private până la spații pentru iniţiative cetățenești și grupuri de autoajutorare. În centrul proiectului se afla metoda de lucru a "proiectării integrale". Prin aceasta se înțelege o metodă de proiectare care este diferită de cea obișnuită prin construirea unei echipe de proiectare interdisciplinare deja în pre-faza proiectării. Permite prin aceasta comunicarea transversală între discipline precum și o integrare legată de ciclul de viață. A fost dezvoltată de Niklaus Kohler. În abordarea mea am proiectat o fațadă reprezentativă către strada principală, pentru a îmbunătăți situaţia urbană la Römerkreis. Această fațadă are umbrire inovativă realizată prin textile legate și în acest sens se conformează principiilor casei pasive. (Fig. 4: Plan, fațade și machetă a elementelor solare la Centrul mediului Heidelberg, 1997, Maria Bostenaru.).

Atriumuri leagă clădirea principală de alte părți ale clădirii, în vreme ce retragerile de sticlă permit o iluminare mai bună la fiecare etaj. În același timp, atriumurile contribuie și la optimizarea energetică de casă pasivă. Studii dedicate cu programe precum DIAS (SIA 1991) au fost folosite pentru calcul al cheltuielilor energetice pentru fațada îmbunătăţită. Au existat preocupări și pentru peisajul zonei. În zona din spate sunt locuințe. În afară de aspectele estetice și funcționale ale proiectării, scopul eficienței economice a clădirii (costuri de construcție) și mai ales de menținere (costuri de urmare) au fost luate în considerare într-o lucrare de economia construcțiilor. În această lucrare am proiectat organizarea, programul, estimarea și controlul costurilor, analiza de utilizare și calcului investițiilor, costurile de funcțiune și de utilizare precum și o variantă de optimizare.

\section{Discuție și concluzii}

În România și Italia nu numai participarea publică, ci și implementarea utilizării energiei regenerabile sunt la într-un stadiu incipient. Totuşi, alte tipuri de energie, cum ar fi energia hidro, beneficiază de experiență considerabilă din perioada dictaturii totalitare, și chiar de dinainte, cum ar fi morile de apă din satul Eftimie Murgu. În cazul energiei solare proiectul anterior pentru Solar Decathlon 2012 în Madrid numit Prispa ${ }^{28}$ a făcut uz de astfel de experienţă tradițională. În Germania, unde energia regenerabilă este mai răspândită și participarea publică este o temă din anii 1960, accentul a fost asupra implicării actorilor, care de asemenea este luat în considerare în analiză.

Conceptul pierde din eficiență în cazul construcțiilor multietajate (precum în cazul proiectului C.A.S.E.). Deși introduse deseori în concept, sera este mai puțin eficientă pentru câștigul maxim decât fereastra simplă, dar își exercită acest rol și în cazul lipsei radiaţiei solare directe. Sera are și un caracter de sporire a calității arhitecturale. O alternativă a serei este atriumul, folosit în studiul de caz german ca alternativă la sera din studiul român.

\footnotetext{
${ }^{27} \mathrm{La}$ al șaptelea concurs al Deutschen Umwelthilfe e.V.(Asociația germană pentru ajutorarea mediului) orașul Heidelberg, aflat la a 800a aniversare, a fost ales orașul ecologic german. Din 2010 titlul de oraș al mediului este decernat la nivel european. http://www.alumni.uni-heidelberg.de/revue/revue_splitter_1_1997_2.html

${ }^{28} \mathrm{http}: / /$ prispa.org/sde2012/echipa/
} 


\section{Integral design project „Environment centre Heidelberg“", Germany, 1997, Maria Bostenaru Dan, supervision Rüdiger Kramm}

For the „German environment city“" ${ }^{629}$ Heidelberg in an exposed site at the Römerkreis I had, as a student at the University of Karlsruhe, under the supervision of Prof. Rüdiger Kramm, the task to design an environment centre: an open house with mixed function, from the headquarters of the environmental authority, institutions, private offices up to spaces for citizen initiatives and self help groups. In the middle of the design project was the working method of the "Integral planning". Through this one understands a planning/design method which is different from the usual design method through the building of an interdisciplinary planning team already in the pre-phase of design. It allows through this both a transversal communication through disciplines, as well as an integration connected to the life cycle. It has been developed by Niklaus Kohler. In my approach I designed a representative façade to the main street, in order to improve the urban planning situation at Römerkreis. This façade has innovative shadowing through connected textiles and in this sense is a passive house (Fig. 4: Plan, facades and model of the solar elements at the Environmental centre Heidelberg.).

Atriums connect the main building with other building parts of the centre, while glass recesses allow for better light in each floor. In the meantime atriums are also contributing the passive house energy optimisation. Dedicated studies with software such as DIAS (SIA 1991) computed the energy consuption of the immproved façade. Thoughts were done also on the landscape design of the area. In the rear zone there are also dwellings. Apart of the aesthetic and functional aspects of design the goal of economic efficiency in building (erection costs) and mainly during the use (consequent costs) were taken into consideration in a building economics work. In this work I planned the design organisation, programme, costs planning and control, use analysis and investition computing, function and use costs were investigated and an optimisation variant was designeed.

\section{Discussion and conclusions}

In Romania and Italy not only public participation, but also implementation of renewable energy projects are at the begin. However, in other types of energy, such as hydroenergy, there is a considerable experience from the totalitarian dictatorship time, and even from before, such as the water mills at Eftimie Murgu village. In case of solar energy a previous project for Solar Decathlon 2012 in Madrid called Prispa ${ }^{30}$ a used such traditional experience. Some other energy forms as wind energy need more investigation in Romania. In Germany, where renewable energy is more spread and public participation is a topic since the 1960s, the accent was on involvment of stakeholders which we also considered in the analysis.

The passive house concept looses from efficiency in case of multistorey buildings (as for C.A.S.E. project). Although frequently introduced in the concept, the winter garden is less efficient for the maximum gain than the simple window, but performs this role also in case of the lack of direct solar radiation. The winter garden has also a character of improving architectural quality. An option different from the winter garden is the atrium, employed in the German case study as alternative to the Romanian one.

\footnotetext{
${ }^{29}$ At the 7th competition of Deutschen Umwelthilfe e.V.(German Association of Environmental Help) the city of Heidelberg, at that moment at the 800th anniversary, had been chosen German Eco-city. Since 2010 the title of Environmental capital is given at European level. http://www.alumni.uni-

heidelberg.de/revue/revue splitter_1_1997 2.html

${ }^{30} \mathrm{http}$ ://prispa.org/sde2012/echipa/
} 
În afară de utilizarea pasivă a energiei solare, aceasta poate fi utilizată și în mod activ, prin colectori termici și panouri fotovoltaice. Din motivul slabei eficiențe la clădiri multietajate a casei pasive, în cazul C.A.S.E. s-au aplicat aceste principii active.

Pentru a face legătura cu rețeaua COST, nevoia de orientare în cazul casei pasive poate avea o influență asupra aspectului cartierelor. Din acest motiv am ales exemple adecvate pentru dezvoltări urbane largi. În cazul casei pasive și peisagistica orientată spre eficiența energetică (Farr, 2008) susține măsurile.

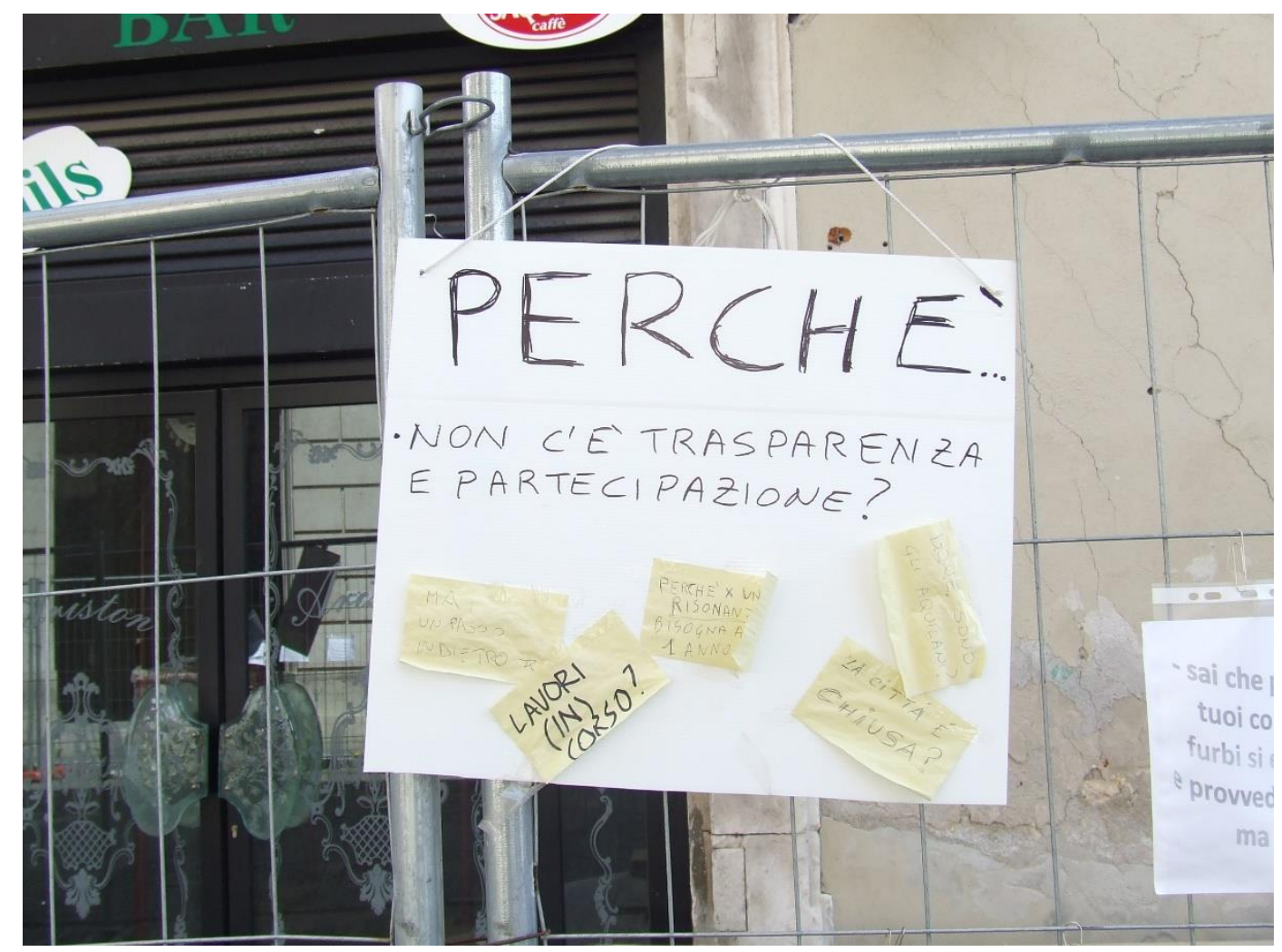

Fig. 3: Protestul locatarilor la L’Aquila. Foto: M. Bostenaru, 2010.

Protest of the inhabitants in L'Aquila. Photo: M. Bostenaru, 2010. 
Apart of the passive employment of solar energy, this can also be used in an active way, through thermal collectors and photovoltaic panels. Because of the low efficiency in multistorey buildings of the passive house, in case of C.A.S.E. project these active principles were applied.

To connect back to the COST action, the orientation need in case of the passive house can have an influence on the looks of the Siedlungen. For this reason we chose examples adequate for a large urban development. In case of the passive house also energy efficient landscaping (Farr, 2008) supports the measure.

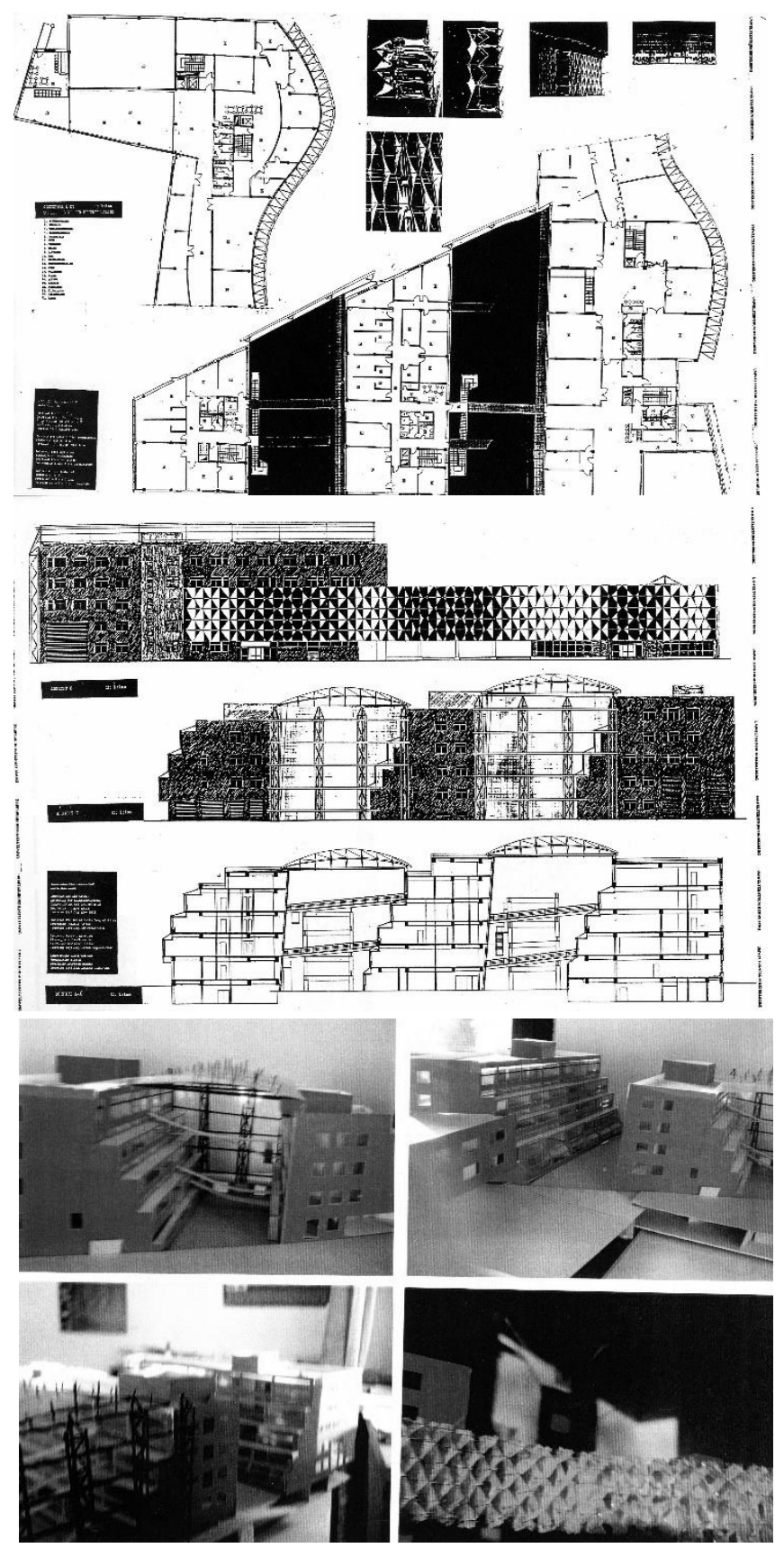

Fig. 1: Plan, fațade și machetă a elementelor solare la Centrul mediului Heidelberg. 1997, Maria Bostenaru Plan, facades and model of the solar elements at the Environmental centre Heidelberg, 1997, Maria Bostenaru. 


\section{Referinţe/References}

Bostenaru Dan, M. (2014). Aspects of Architecture and Urbanism in the Reconstruction of Disaster: Comparison of L' Aquila (Italy) with Kolontar/Devecser (Hungary) and Corbeni (Romania) in the Context of Participative Reconstruction. In M. Bostenaru Dan, I. Armas și A. Goretti (coord.), Earthquake Hazard Impact and Urban Planning (pp 259-291), Springer.

Calvi, G.M., Spaziante, V. (2009). La ricostruzione tra provvisorio e definitivo: il Progetto C.A.S.E., Progettazione Sismica, 1, 3.

Cerqua, A., Rapicetta, S. (2014) A Proposal to Improve the Disaster Management Cycle Model: the Importance of Community Participation. In M. Bostenaru Dan, I. Armas și A. Goretti (coord.), Earthquake Hazard Impact and Urban Planning (pp 249-257), Springer.

Gonzalo, R., Habermann, K. J. (2012) Energy-Efficient Architecture. Basics for Planning and Construction, Birkhäuser.

Goulding, J.R., Owen Lewis, J., Steemers, T.C. (1992). Energy in architecture : the European passive solar handbook, London : B.T. Batsford for the Commission of the European Communities, Directorate General XII for Science, Research and Development.

Farr, D. (2008). Sustainable urbanism. Urban design with nature. Hoboken: Wiley.

Mihăescu, O., Ghilduş, M. (2012). PRISPA, a New Vision in Romanian Architectural Education, International Conference of Architectural Research, ICAR 2012, Bucharest.

Onescu-Tărbujaru, D., Leca, A.L., Din, A.-M. (2015). IC-089 Two Projects, Two Teams, Two Houses: Prispa And EfdeN At Solar Decathlon Europe, International Conference of Architectural Research, ICAR 2015, Bucharest.

Onescu-Tărbujaru, D., Leca, L. (2014). PRISPA post Madrid, Argument 6/2014, 373-391.

Schittich, C. (coord.) (2003). Solar architecture, Birkhäuser.

Schoof, J. (2012) Abschied von der Verzichtsästhetik: Die Bauten des Solar Decathlon 2012, Detail Green 2/2012.

SIA D 010 (1991) «Handbuch der passiven Sonnenenergienutzung»

Stahl, W., Goetzberger, A. (1990). Das energieautarke Solarhaus. Sonnenenergie, Heft 6/1990, 11-19.

Turino, R. (Ed.) (2010). L'Aquila. Il progetto C.A.S.E., Pavia: IUSS Press.

\section{Referințe web/Web references}

Pagina Protecției Civile Italiene

http://www.protezionecivile.gov.it/jcms/it/view_dossier.wp?contentId=DOS274

Accesat 15.11.2017 